\title{
A torso model comparison of temperature preservation devices for use in the prehospital environment
}

\author{
Michele Zasa, ${ }^{1,2}$ Neil Flowers, ${ }^{1}$ David Zideman, ${ }^{1}$ Timothy J Hodgetts, ${ }^{1}$ Tim Harris ${ }^{1,3}$
}

${ }^{1}$ East Anglian Air Ambulance, Helicopter Emergency Medical Service, Hangar D, Gambling Close, Norwich Airport, Norwich, UK

${ }^{2}$ Clinica Mobile nel Mondo, World Motorbike Championships (MotoGP \& WSBK) Medical Division, Parma, Italy

${ }^{3}$ Academic Department Emergency Medicine, Queen Mary University London and Barts Health NHS Trust, London, UK

\section{Correspondence to} Professor Tim Harris, East Anglian Air Ambulance, Helicopter Emergency Medical Service, Hanger D, Gambling Close, Norwich Airport, Norwich NR6 6EG, UK: tim.harris@bartshealth.nhs.uk

Received 6 March 2015 Revised 11 January 2016 Accepted 12 January 2016 Published Online First 2 February 2016

\section{ABSTRACT \\ Background Hypothermia is an independent predictor of increased morbidity and mortality in patients with trauma. Several strategies and products have been developed to minimise patients' heat loss in the prehospital arena, but there is little evidence to inform the clinician concerning their effectiveness.}

Methods We used a human torso model consisting of two 5.5-litre fluid bags to simultaneously compare four passive (space blanket, bubble wrap, Blizzard blanket, ambulance blanket) and one active (Ready-Heat II blanket) temperature preservation products. A torso model without any temperature preservation device provided a control. For each test, the torso models were warmed to $37^{\circ} \mathrm{C}$ and left outdoors. Core temperatures were recorded every $10 \mathrm{~min}$ for $1 \mathrm{~h}$ in total; tests were repeated 10 times.

Results A significant difference in temperature was detected among groups at 30 and $60 \mathrm{~min}(\mathrm{~F}(1.29,10.30)$ $=103.58, p<0.001$ and $F(1.64,14.78)=163.28$,

$p<0.001$, respectively). Mean temperature reductions (95\% $\mathrm{Cl})$ after $1 \mathrm{~h}$ of environmental exposure were the following: $11.6(10.3 \text { to } 12.9)^{\circ} \mathrm{C}$ in control group, 4.5 (3.9 to 5.1) ${ }^{\circ}$ $\mathrm{C}$ in space blanket group, 3.6 (3 to 4.3$)^{\circ} \mathrm{C}$ in bubble-wrap group, 2.1 (1.7 to 2.5$)^{\circ} \mathrm{C}$ in Blizzard blanket group, 6.1 (5.8 to 6.5$)^{\circ} \mathrm{C}$ in ambulance blanket group and 1.1 (0.7 to 1.6$)^{\circ} \mathrm{C}$ in Ready-Heat II blanket group.

Conclusions In this study, using a torso model based on two $5 \mathrm{~L}$ dialysate bags we found the Ready-Heat II heating blanket and Blizzard blanket were associated with lower rates of heat loss after 60 min environmental exposure than the other devices tested.

\section{INTRODUCTION}

Hypothermia, defined as a core temperature below $35^{\circ} \mathrm{C},{ }^{1}$ is known to have several detrimental effects on human physiology including cardiac, pulmonary, neurological and haemostatic systems. ${ }^{2}$ Hypothermia has been associated with increased morbidity and mortality in patients with trauma, ${ }^{13-5}$ and together with acidosis and coagulopathy it represents the 'lethal triad' of trauma. ${ }^{6}$ Cold is also an unpleasant sensation for our patients. Therefore, hypothermia prevention is an important part of the prehospital care provided to injured patients. While most trauma victims are vulnerable to hypothermia anaesthetised patients are particularly at risk as a consequence of anaesthesia-related impairment of thermoregulation. ${ }^{7}$

A range of products have been developed to reduce heat loss and/or actively warm patients in

\section{Key messages}

What is already known on this subject? Heat loss is common in the prehospital environment. Hypothermia is unpleasant for patients and may be associated with increased mortality and morbidity. There are several mechanisms and devices to conserve temperature. There is a paucity of data to guide clinicians in their choice of strategy.

What might this study add? In this torso model, we demonstrated that the passive Blizzard blanket system and Ready-Heat II active rewarming blanket system were associated with significantly higher torso model temperatures after $1 \mathrm{~h}$ environmental exposure compared with bubble-wrap thermal bag system, the space blanket or polyester ambulance blanket. No devices prevented heat loss or increased the torso temperature at 30 or $60 \mathrm{~min}$.

the prehospital environment. Active external systems generate heat that is directly transferred to the patient while passive systems insulate the patient, avoiding body heat dispersion. These can be combined to maximise effects. Studies to compare different strategies and devices are inconclusive, with no consensus on which to apply. ${ }^{8-12}$

We set out to develop a model to compare the different hypothermia prevention systems currently available for use in a Helicopter Emergency Medical Services (HEMS) system.

\section{MATERIALS AND METHODS}

We developed a human torso model consisting of two $5.5 \mathrm{~L}$ bags of Diasol 7081 (Baxter, Zurich, Switzerland) dialysate solution. An indwelling thermistor probe (AccuPRO, PROACT Medical, Corby, UK) was placed between the two bags, and the model was bound together with tape. The models were placed in a calibrated warming cabinet $(\bmod$ W330, LEEC, Nottingham, UK) set to a temperature of $37^{\circ} \mathrm{C}$. The study was conducted at an HEMS base in a UK airfield. The temperatures used in this study, therefore, reflect those in which we, and most UK retrieval services, treat and retrieve patients in the UK winter. As such we regard temperature management as part of our active treatment for both patient comfort and homeostasis. 
For each test, six human torso models were simultaneously removed from the warming cabinet, and in five one of the heat preservation systems under investigation was applied. In one model (control group), no heat preservation system was used. The six torso models were assumed to be equivalent and were randomly allocated to the different devices at each measurement.

The following products were tested: Ready-Heat II active rewarming blanket (TechTrade, New York, USA), Blizzard EMS blanket (Blizzard Protection Systems, Gwynedd, UK), bubblewrap thermal bag (mod LS 3010, Less AS, Kapp, Norway), space blanket (Farmac-Zabban SpA, Calderara di Reno BO, Italy) and the fire-retardant polyester ambulance blanket (Thomas Kneale, Manchester, UK).

Each torso model was wrapped with one layer of the designated test system, as per the manufacturer's guidance. The Ready-Heat II blanket was opened 20 min before starting the study and agitated to allow chemical activation and heat production. A layer of cotton sheet was interposed between the Ready-Heat II warming blanket and the torso model, in accordance with clinical practice to avoid skin burns.

Once prepared, all torso models (including the control) were simultaneously moved outside and placed on three plastic orthopaedic transport stretchers (Scoop 65 EXL, Ferno-Washington, Wilmington, USA) previously positioned on the ground. These orthopaedic stretchers were placed outside on the airfield 5 min before the start of the test, $10 \mathrm{~m}$ apart and perpendicular to the wind direction (as determined by the airfield windsock). Each stretcher carried two study models, placed $20 \mathrm{~cm}$ apart. All model torsos, therefore, had consistent wind exposure.

Temperature changes were recorded using a monitor (Argus PRO Lifecare 2, Schiller AG, Baar, Switzerland) connected to each indwelling thermistor probe. Five seconds were allowed for calibration and the temperature recorded, then the probe was disconnected and moved to the next model.

For each test session, temperatures were checked every $10 \mathrm{~min}$ for $1 \mathrm{~h}$. The study was performed on 10 separate days.

The sequence in which the study heat preservation systems were applied to the torso models and temperatures measured were different for each study day. This was predetermined by using a random sequence generator (Random Sequence Generator, available at http://random.org/sequences/; last accessed 15 Feb 2013).

Temperature, humidity and wind speed were recorded from airport air traffic control.

In order to avoid observer bias, the investigator responsible for statistical analysis was neither involved in data collection, nor aware of group assignment.

\section{Statistical analysis}

The primary endpoint of the study was to compare temperatures among tested models after $60 \mathrm{~min}$ of environmental exposure; temperature comparison after $30 \mathrm{~min}$ was set as a secondary endpoint. Temperatures were compared using a one-way analysis of variance test, with post hoc Bonferroni comparisons to analyse between-groups differences. A p value $\leq 0.05$ was considered significant. Both at 30 and 60 min 15 post hoc comparisons were performed, and an adjusted $\mathrm{p}$ value was reported; again, a $p$ value $\leq 0.05$ was considered significant. The statistical software automatically reported adjusted $\mathrm{p}$ values (multiplying the $\mathrm{p}$ value by the number of tests). Data are presented as mean values $( \pm S D)$, unless otherwise specified. The software SPSS (IBM SPSS Statistics V.20; Armonk, USA) was used to perform statistical analyses.
Table 1 Environmental conditions during test sessions (initial and final values)

\begin{tabular}{|c|c|c|c|c|c|c|}
\hline & \multicolumn{2}{|l|}{$\mathrm{T}\left({ }^{\circ} \mathrm{C}\right)$} & \multicolumn{2}{|l|}{ H (\%) } & \multicolumn{2}{|c|}{ WS (knots) } \\
\hline & Time 0 & Time 60 & Time 0 & Time 60 & Time 0 & Time 60 \\
\hline Test 1 & 4 & 4 & 82 & 75 & 10 & 7 \\
\hline Test 2 & 5 & 5 & 74 & 74 & 10 & 10 \\
\hline Test 3 & 0 & 1 & 80 & 86 & 12 & 8 \\
\hline Test 4 & 0 & 0 & 100 & 100 & 3 & 3 \\
\hline Test 5 & 2 & 2 & 96 & 95 & 1 & 1 \\
\hline Test 6 & 2 & 1 & 95 & 98 & 1 & 1 \\
\hline Test 7 & -3 & -3 & 100 & 100 & 0 & 1 \\
\hline Test 8 & -3 & -3 & 100 & 100 & 1 & 1 \\
\hline Test 9 & 2 & 3 & 77 & 77 & 3 & 4 \\
\hline Test 10 & 2 & 4 & 77 & 74 & 4 & 4 \\
\hline
\end{tabular}

$H$, humidity; T, temperature; WS, wind speed.

\section{RESULTS}

The study environmental conditions during the study period are described in table 1. The temperatures of each torso model are displayed in figure 1 .

Significant differences in temperatures were detected among groups both after 30 and $60 \mathrm{~min}$ of environmental exposure $(\mathrm{p}<0.001$ and $\mathrm{p}<0.001$, respectively).

Comparison between groups at 30 and $60 \mathrm{~min}$ are shown in table 2 . At both time points, all heat preservation systems tested resulted in a higher mean torso model temperature than the control torso model (all $\mathrm{p} \leq 0.003$ ). The statistical analysis is reported in table 2 .

At $30 \mathrm{~min}$, the Ready-Heat II active heating system was associated with significantly less heat loss than all other tested devices and in the first $10 \mathrm{~min}$ the torso model temperature increased (figure 2).

At $60 \mathrm{~min}$, the Ready-Heat II heating blanket (an active system) and Blizzard blanket (passive system) demonstrated the lowest heat loss and highest temperatures in the torso models. There was no statistical difference in the performance of these two devices $(p=0.250)$ and both were significantly better than the other systems tested (figure 3).

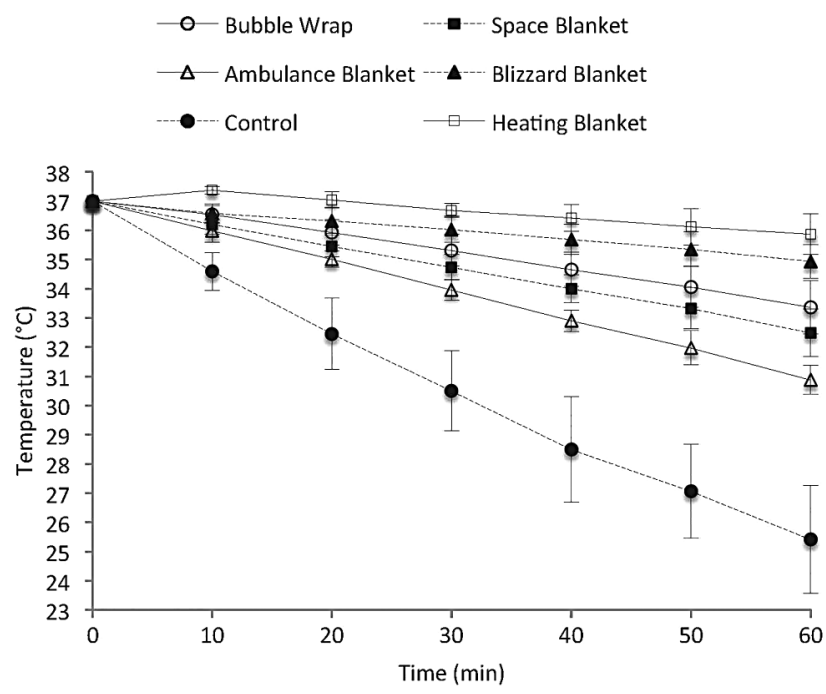

Figure 1 The rate of temperature loss for each device over $60 \mathrm{~min}$. Data presented as mean values $( \pm \mathrm{SD})$. 
Table 2 Comparison of temperatures of torso models after 30 and 60 min of environmental exposure

\begin{tabular}{|c|c|c|c|c|}
\hline & $\begin{array}{l}\mathrm{T} \text { at } \\
30 \mathrm{~min} \\
\left({ }^{\circ} \mathrm{C}\right)\end{array}$ & $\begin{array}{l}\text { Adjusted } \\
\text { p value } \\
<0.05\end{array}$ & $\begin{array}{l}\mathrm{T} \text { at } \\
60 \mathrm{~min} \\
\left({ }^{\circ} \mathrm{C}\right)\end{array}$ & $\begin{array}{l}\text { Adjusted } \\
\text { p value } \\
<0.05\end{array}$ \\
\hline Heating blanket & $36.7 \pm 0.2$ & $\begin{array}{l}\text { Blizzard } \\
\text { Bubble } \\
\text { Space } \\
\text { Ambulance }\end{array}$ & $35.9 \pm 0.7$ & $\begin{array}{l}\text { Bubble } \\
\text { Space } \\
\text { Ambulance }\end{array}$ \\
\hline Blizzard blanket & $36.0 \pm 0.4$ & $\begin{array}{l}\text { Heating } \\
\text { Space } \\
\text { Ambulance }\end{array}$ & $34.9 \pm 0.6$ & $\begin{array}{l}\text { Bubble } \\
\text { Space } \\
\text { Ambulance }\end{array}$ \\
\hline Bubble wrap & $35.3 \pm 0.5$ & $\begin{array}{l}\text { Heating } \\
\text { Space } \\
\text { Ambulance }\end{array}$ & $33.4 \pm 0.9$ & $\begin{array}{l}\text { Heating } \\
\text { Blizzard } \\
\text { Ambulance }\end{array}$ \\
\hline Space blanket & $34.7 \pm 0.4$ & $\begin{array}{l}\text { Heating } \\
\text { Blizzard } \\
\text { Bubble } \\
\text { Ambulance }\end{array}$ & $32.5 \pm 0.8$ & $\begin{array}{l}\text { Heating } \\
\text { Blizzard } \\
\text { Ambulance }\end{array}$ \\
\hline Ambulance blanket & $33.9 \pm 0.4$ & $\begin{array}{l}\text { Heating } \\
\text { Blizzard } \\
\text { Bubble } \\
\text { Space }\end{array}$ & $30.9 \pm 0.4$ & $\begin{array}{l}\text { Heating } \\
\text { Blizzard } \\
\text { Bubble } \\
\text { Space }\end{array}$ \\
\hline Control* $^{*}$ & $30.5 \pm 1.4$ & All & $25.4 \pm 1.8$ & All \\
\hline
\end{tabular}

\section{DISCUSSION}

In this study, none of the heat preservation devices were able to prevent heat loss from the torso model; however, all were effective in reducing the degree of heat loss compared with the control. The Ready-Heat II heating blanket (active rewarming system) and the Blizzard blanket (passive system) preserved temperature significantly more efficient than the other systems studied with no statistical difference between the torso model temperatures at $60 \mathrm{~min}$. The Ready-Heat II heating blanket was associated with an increase in temperature of the torso model in the initial $10 \mathrm{~min}$ of the study. It also resulted in a significantly higher temperature than all devices, including the Blizzard blanket, at $30 \mathrm{~min}$. The difference in measured torso temperatures increased with time suggesting that more efficient heat preservation systems are increasingly effective with increasing on-scene times. In the UK these most commonly range 30$60 \mathrm{~min}$ (audit data from our services).
Maintenance of body temperature is important for both trauma victims' comfort and homeostasis, with hypothermia associated with poor outcomes in many studies. ${ }^{13-5}$ However, in a recent prognostic modelling study hypothermia was not identified as an independent predictor of death. ${ }^{13}$ However, hypothermia was found to be a predictor of haemorrhage and coagulopathy. This retrospective study was limited by incomplete data.

In a study similar to ours Allen et $a l^{9}$ used nine 5-litre dialysate solution heated bags to replicate a human torso, which was wrapped in different heat preservation devices and then placed in a room with a temperature between $22.3^{\circ} \mathrm{C}$ and $22.7^{\circ} \mathrm{C}$. The authors reported the most effective heat preservation system was a combination of an active and a passive device (Hypothermia Prevention and Management Kit), with active systems alone performing better than passive ones alone. However, some passive systems (Hot Pocket and Blizzard blanket) performed similarly to two active heating systems at $120 \mathrm{~min}$ exposure. This study was performed at room temperature, which is not representative of the prehospital environment both in terms of ambient temperature and wind. Hence, our study exposed the torso models to temperatures from $-3^{\circ} \mathrm{C}$ to $+5^{\circ} \mathrm{C}$.

However, in contrast to the Allen study, Lundgren et al ${ }^{10}$ failed to detect any superiority of an active/passive combined system over a passive system alone. In their randomised clinical trial, Lundgren et al examined the benefit of warming systems by adding a chemical heat pad to a blanket. The authors recruited 48 patients with trauma transported to the hospital by helicopter or ambulance, with air temperature set to $25^{\circ} \mathrm{C}$ in the transportation unit. Study results showed that additional active warming did not significantly improve core temperature. However, patients with an altered initial level of consciousness were not enrolled, and mean Revised Trauma Score ${ }^{14}$ for the study population was relatively high: 7.83 (7.55-7.84). Therefore, study results may only be applied to less severely injured, spontaneously ventilating patients, with preserved shivering capacity.

Consistent with results presented by Lundgren et al, Johnson et $a l^{11}$ did not find a significant difference between the use of a passive preventive system alone and its association with active thermal inserts. This study used a porcine model; animals were anaesthetised, haemorrhaged and moved to a cooler (set at $10^{\circ} \mathrm{C}$ ) to simulate a cold environment. Heat prevention was performed with the HEET garment (Trident Industries,

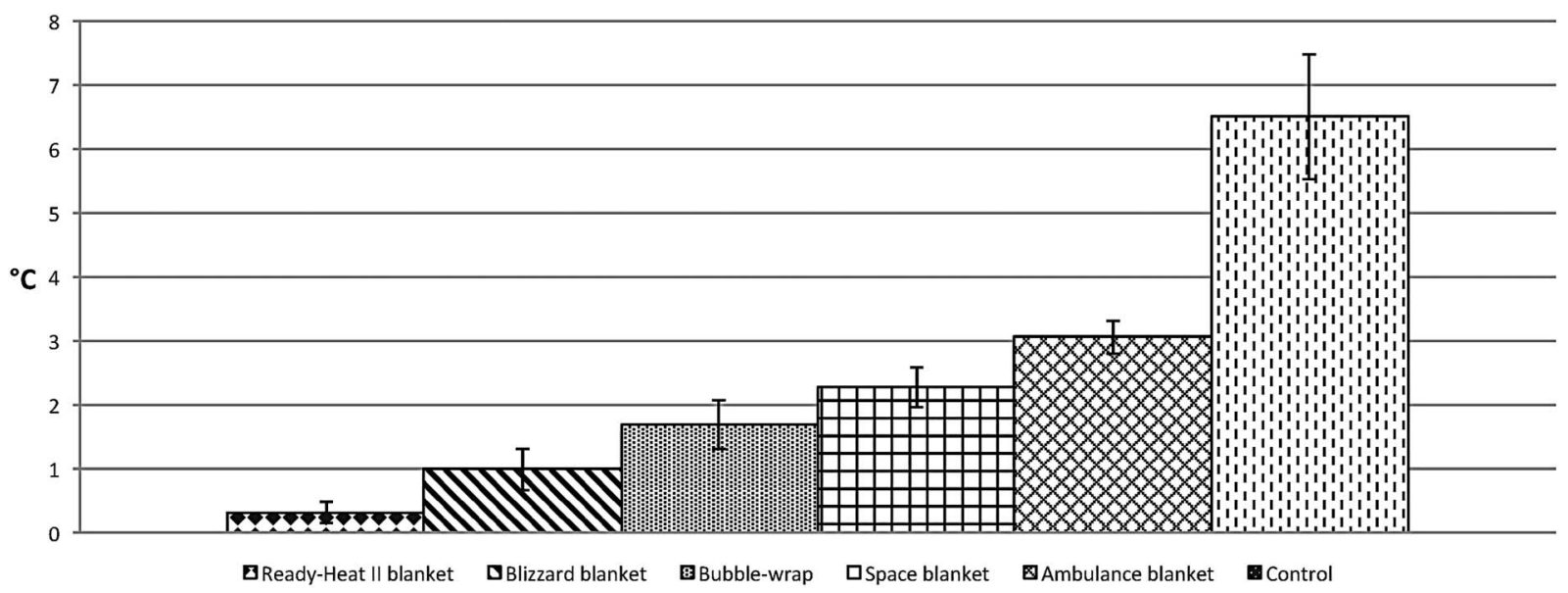

Figure 2 Visual comparison of the mean loss of temperature $(95 \% \mathrm{Cl})$ after $30 \mathrm{~min}$. 


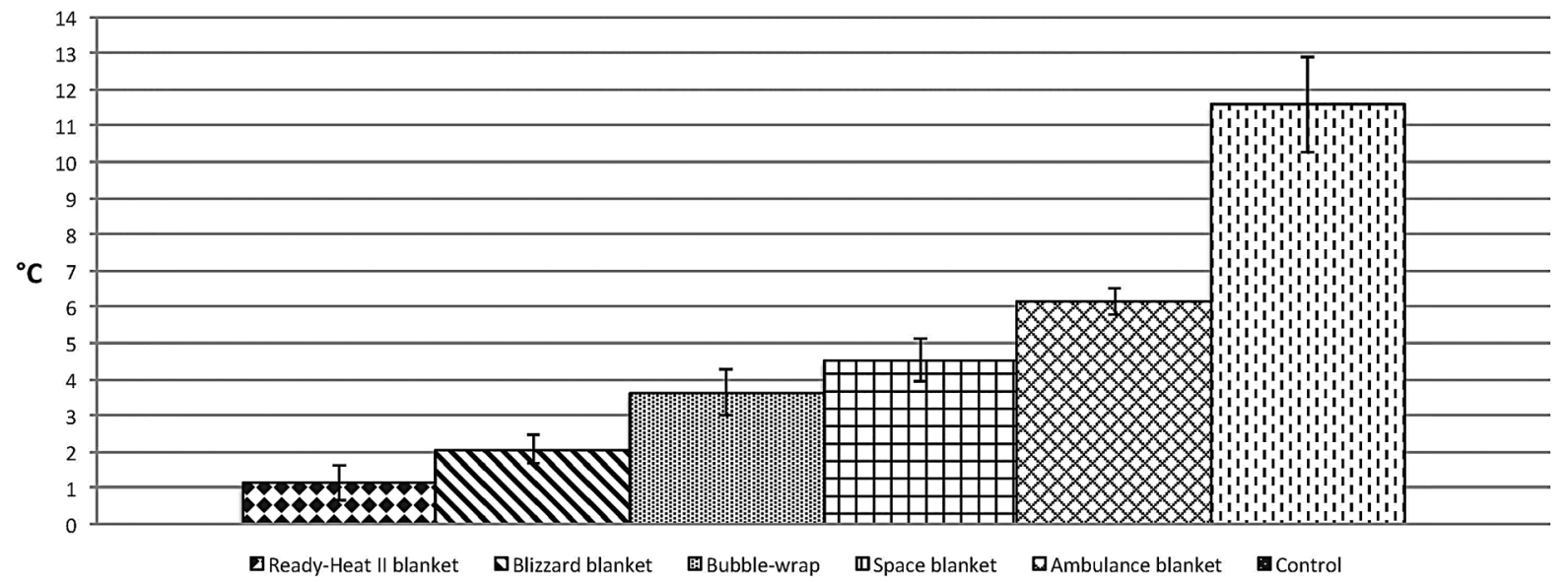

Figure 3 Visual comparison of the mean loss of temperature $(95 \% \mathrm{Cl})$ after $60 \mathrm{~min}$.

Beaufort, USA), a multilayer passive system designed to prevent heat convection, conduction, evaporation and radiation. The HEET garment was used alone or in combination with air activated heat packs and a control group was covered with two wool blankets. Core body temperatures were recorded every hour over $6 \mathrm{~h}$. None of the study devices was effective in preventing hypothermia, but the control group was the most effective method in slowing the onset of hypothermia. No statistical differences were found between the use of a HEET garment alone and in combination with thermal inserts, and final authors' recommendation was not to use HEET garments to prevent or treat hypothermia in operational environments.

Resistive rewarming in the prehospital environment was studied by Kober $e t a l^{12}$ in patients with minor trauma, most of whom were mildly hypothermic. All enrolled patients were covered with a resistive heating blanket and a wool blanket at the scene of injury, but only half of them had the resistive blanket activated. The resistive system was able to increase body temperatures by $0.8^{\circ} \mathrm{C}$, while in the passive rewarming group temperature decreased by $0.4^{\circ} \mathrm{C}(\mathrm{p}<0.001)$. A limitation of this study was that only minor trauma victims were enrolled, so the efficiency in sicker or ventilated patients without the capacity to shiver is not known.

Finally, Thomassen et $a l^{8}$ compared three different passive systems (ambulance blanket, bubble wrap and Hibler's method-a combination of tight layer and dry insulating layer) on healthy volunteers. The study population was dressed in wet clothes, and placed in a cold climatic chamber at $3^{\circ} \mathrm{C}$ and $3 \mathrm{~m} / \mathrm{s}$ wind. Core temperatures were not significantly different among study groups, although skin temperature was significantly higher in Hibler's method group and metabolic heat production was higher with bubble wrap. The authors' conclusion was that Hibler's method is an effective and simple way to prevent heat loss, and therefore should be the method of choice when wrapping wet patients in prehospital environments. However, the study enrolled healthy volunteers, and therefore the results may not be predictive of real case scenarios involving severely injured patients.

\section{Limitations}

Our study has some clear limitations. As per Allen et al study, ${ }^{8}$ findings may not be extrapolated to human beings, as the model did not reproduce human metabolic basal activity and hypothermic physiological responses. The specific heat capacity of the human body is around $3470 \mathrm{~J} / \mathrm{kgK}$ while that of water is around $4186 \mathrm{~J} / \mathrm{kgK}$, thus the torso models would cool more slowly than a human body, which may offset this issue to some degree. We aimed to use large fluid-filled bags to get as close as possible to human torso volume:body surface area and the dialysate bags were the largest cost-effective model we could identify. However, our study aimed to evaluate intrinsic properties of studied devices, and describe their capacity to prevent heat loss and the torso model ensured equal test conditions for each product. Patients with major trauma often require prehospital anaesthesia; in this group of patients physiological responses to heat loss are often diminished due to the severity of injuries and response to anaesthetic drugs so the torso model may apply more closely to anaesthetised than spontaneously ventilating patients. ${ }^{7}{ }^{15}$ Further research using randomised clinical trials comparing studied devices on patients with major trauma is required to identify the best heat preservation strategy but informed consent would be challenging and such studies expensive to perform.

In the present study, we did not compare all industry available heat preservation devices and we did not include any combined active/passive system.

\section{CONCLUSIONS}

In this study, using a torso model based on two $5 \mathrm{~L}$ dialysate bags we found the Ready-Heat II heating blanket and Blizzard blanket were associated with lower rates of heat loss after $60 \mathrm{~min}$ environmental exposure than the other devices tested. Following $30 \mathrm{~min}$ exposure the Ready-Heat II active heating system was associated with significantly better temperature preservation.

Twitter Follow Tim Harris at @tim harris@resusdocs

Acknowledgements In order to perform the study LEEC (Nottingham, UK) provided a warming cabinet during the study period, Baxter (Zurich, Switzerland) donated bags of 5.5L dialysate solution and Blizzard Protection Systems (Gwynedd, UK) donated samples of the Blizzard blanket. The authors would like to thank the above-mentioned companies for their contribution to the study.

Contributors All authors conceived the study and contributed to study design. MZ and NF performed the study. MZ, NF and TH wrote the paper. All authors reviewed and contributed to the final manuscript.

Competing interests None declared.

Provenance and peer review Not commissioned; externally peer reviewed.

\section{REFERENCES}

1 Søreide K. Clinical and translational aspects of hypothermia in major trauma patients: from pathophysiology to prevention, prognosis and potential preservation. Injury 2014;45:647-54.

2 Tsuei BJ, Kearney PA. Hypothermia in the trauma patient. Injury 2004; 35:7-15.

3 Beilman GJ, Blondet JJ, Nelson TR, et al. Early hypothermia in severely injured trauma patients is a significant risk factor for multiple organ dysfunction syndrome but not mortality. Ann Surg 2009;249:845-50. 
4 Peng RY, Bongard FS. Hypothermia in trauma patients. J Am Coll Surg 1999;188:685-96.

5 Wang $\mathrm{HE}$, Callaway CW, Peitzman AB, et al. Admission hypothermia and outcome after major trauma. Crit Care Med 2005;33:1296-301.

6 Moffatt SE. Hypothermia in trauma. Emerg Med J 2013;30:989-96.

7 Langhelle A, Lockey D, Harris T, et al. Body temperature of trauma patients on admission to hospital: a comparison of anaesthetised and non-anaesthetised patients. Emerg Med J 2012;29:239-42.

8 Thomassen $\varnothing$, Færevik $H$, Østerås $\varnothing$, et al. Comparison of three different prehospital wrapping methods for preventing hypothermia-a crossover study in humans. Scand I Trauma Resusc Emerg Med 2011;19:41.

9 Allen PB, Salyer SW, Dubick MA, et al. Preventing hypothermia: comparison of current devices used by the US Army in an in vitro warmed fluid model. J Trauma 2010;69:S154-61.
10 Lundgren $\mathrm{P}$, Henriksson $\mathrm{O}$, Naredi $\mathrm{P}$, et al. The effect of active warming in prehospital trauma care during road and air ambulance transportation - a clinical randomized trial. Scand J Trauma Resusc Emerg Med 2011;19:59.

11 Johnson D, Gegel B, Burgert J, et al. Effects of the HEET garment in the prevention of hypothermia in a porcine model. J Surg Res 2010;164:126-30.

12 Kober A, Scheck T, Fülesdi B, et al. Effectiveness of resistive heating compared with passive warming in treating hypothermia associated with minor trauma: a randomized trial. Mayo Clin Proc 2001;76:369-75.

13 Trentzsch $\mathrm{H}$, Huber-Wagner $\mathrm{S}$, Hildebrand $\mathrm{F}$, et al. Hypothermia for prediction of death in severely injured blunt trauma patients. Shock 2012;37:131-9.

14 Champion HR, Sacco WJ, Copes WS, et al. A revision of the trauma score. J Trauma 1989:29:623-9.

15 Sessler DI. Temperature monitoring and perioperative thermoregulation. Anesthesiology 2008;109:318-38. 